\title{
Starch-Based Microparticles as Vehicles for the Delivery of Active Platelet-Derived Growth Factor
}

\author{
GABRIEla A. SILVA, Ph.D., ${ }^{1,2}$ OLGA P. COUTINHO, Ph.D., ${ }^{3}$ PAUL DUCHEYNE, Ph.D., ${ }^{4}$ \\ IRVING M. SHAPIRO, Ph.D., ${ }^{5}$ and RUI L. REIS, Ph.D. ${ }^{1,2}$
}

\begin{abstract}
In a previous work, we described the use of starch-based microparticles as vehicles for the controlled release of corticosteroids. The goal of the present work is to evaluate the potential of these microparticles to incorporate and release platelet-derived growth factor (PDGF). The loading efficiency and release profile were evaluated, and PDGF was incorporated into and released from the matrix of starch-based microparticles. The release profile shows rapid release of PDGF in the first $24 \mathrm{~h}$, after which there was a slow but constant release for up to 8 weeks. The maintenance of the PDGF biological activity after incorporation and release was evaluated by its mitogenic effect over osteoblastic cells, and it was shown to be comparable to that of PDGF supplemented to the culture medium. This proves that the incorporation and release did not affect the biological activity of the growth factor (GF). The results clearly demonstrate that starchbased microparticles are suitable vehicles for the incorporation and release of GFs. When combined with previous results, these materials also suggest their ability to enhance the regenerating potential of tissue engineering hybrid constructs.
\end{abstract}

\section{INTRODUCTION}

$\mathbf{I}^{\mathrm{r}}$ NISSUE ENGINEERING, there has been considerable interest in the use of growth factors (GFs) to enhance regeneration and achieve faster repair of bones.

Among GFs of potential interest is the platelet-derived growth factor (PDGF). PDGF is a polypeptide dimer with a molecular mass of 30,000. A well-known mitogen for cells of mesenchymal origin, ${ }^{1-4}$ it was initially isolated from platelets but subsequently found to be synthesized by a variety of skeletal and nonskeletal cells. ${ }^{5}$ This GF has three different isoforms, each a dimeric combination of two distinct, but structurally related, peptide chains: $\mathrm{AA}, \mathrm{AB}$, and $\mathrm{BB}^{6-8}$ These isoforms are differently expressed in various cell types.
They also differ in the specific binding to two cell receptors: PDGFr- $\alpha$ and PDGFr- $\beta{ }^{6-8}$

PDGF isoforms have been found to be mitogenic for several cell lineages, an effect apparently mediated by the mitogen activated protein (MAP) kinase pathway. ${ }^{9}$ Bone regeneration and repair, like other tissue healing processes, involve a complex cascade of events, including chemotactic, proliferative, and maturational phases. ${ }^{2}$ PDGF is known to act in the earlier phases, promoting cell chemotaxis ${ }^{10-12}$ and proliferation, ${ }^{5}$ but not in the maturation or differentiation of osteoblast cells. ${ }^{13,14}$ PDGF has also been shown to stimulate migration and to increase the proliferation rate of osteoblasts in vitro, ${ }^{15,16}$ reduce alkaline phosphatase activity, ${ }^{16}$ and inhibit bone matrix formation. ${ }^{17}$

\footnotetext{
${ }^{1}$ 3B's Research Group-Biomaterials, Biodegradables and Biomimetics, University of Minho, Campus de Gualtar, Braga, Portugal.

${ }^{2}$ Department of Polymer Engineering, University of Minho, Campus de Azurém, Guimarães, Portugal.

${ }^{3}$ Department of Biology, Center of Biology, University of Minho, Campus de Gualtar, Braga, Portugal.

${ }^{4}$ Center for Bioactive Materials and Tissue Engineering, University of Pennsylvania, Philadelphia, Pennsylvania.

${ }^{5}$ Department of Orthopaedic Surgery, Thomas Jefferson University, Philadelphia, Pennsylvania.
} 
The combination of scaffold materials with cells specific for the defect site is an attractive means of creating a tissue engineering construct capable of promoting regeneration. The supplementation with GFs is intended to improve the efficacy of bone formation. ${ }^{18}$ The GF incorporated within the matrix of the scaffold serves not only as a support material but also as a release device. Biodegradable scaffolds are most desirable for such applications, as they serve only temporarily, being replaced as new tissue is formed.

However, during processing of the scaffold, the bioactive molecules may often be inactivated by solvents or processing temperature. To avoid such limitations, we propose that a bioactive molecule (in this case, a GF) be incorporated into starch-based, biodegradable, micron-sized particles, produced at room temperature and by a simple emulsion method. As part of the new strategy, these microparticles would then be combined with a cell population (stem/progenitor cells) to form a 3-D structure. The GF released from these particles would directly target the cells at the surface of the materials, acting to enhance their proliferation and differentiation. The biodegradable nature of the starch microparticles would allow them to be replaced by newly formed tissue in the in vivo location at a later stage. This strategy will be particularly useful when using cells isolated from the patient, which are usually limited in supply.

Starch-based materials have been studied for biomedical applications, not only as scaffolds, ${ }^{19-22}$ but also as bone cements ${ }^{23,24}$ and microparticles. ${ }^{25-27}$ They are found to be biocompatible in vitro ${ }^{28-30}$ and also perform well in vivo. ${ }^{31,32}$ Previous studies have also shown that they can support cell adhesion at their surface, as well as proliferation and expression of osteoblastic marker genes by the adhered cells. ${ }^{33}$ Therefore, in this work, we explore the capability of starchbased microparticles to incorporate PDGF and release it in a sustained manner. We also explore their use as carriers for GFs, as starch-based microparticles have already been shown to be bioactive through formation of a calciumphosphate layer in vitro, ${ }^{25}$ to release other biologically active molecules in a sustained way; ${ }^{34}$ and to support cell adhesion, proliferation, and phenotypic expression of osteoblastic markers. ${ }^{33}$

\section{MATERIALS AND METHODS}

\section{Materials}

A blend of $50 \%$ corn starch and $50 \%$ polylactic acid (PLA) by weight (PLA 4040 [94\% L-Lactide] was obtained from Cargill-Dow [Minneapolis, MN] and the blended material was supplied by Novamont [Novara, Italy]), designated as starch with polylactic acid (SPLA), was used as the raw material. Human recombinant platelet-derived growth factor-BB (hPDGF-BB) was purchased from R\&D systems (Minneapolis, MN).
The cell line used in this work was MC3T3-E1, subclone 4 , derived from fetal mouse calvaria, and was purchased from American Tissue Cell Collection (ATCC). The cells were cultured in Dulbecco's modified Eagle's medium (DMEM) supplemented with 10\% fetal bovine serum (FBS) and $1 \%$ antibiotics (penicillin and streptomycin) and cultivated under standard tissue culture conditions $\left(37^{\circ} \mathrm{C}, 5 \%\right.$ carbon dioxide $\left[\mathrm{CO}_{2}\right]$ ).

\section{Synthesis of PDGF-SPLA microparticles}

Briefly, and as described earlier, ${ }^{25} 1 \mathrm{~g}$ of SPLA powder was partially dissolved in $10 \mathrm{~mL}$ of methylene chloride for approximately $15 \mathrm{~min}$. The SPLA-methylene chloride solution was then added dropwise to $200 \mathrm{~mL}$ of $0.5 \%$ polyvinyl alcohol (PVA) solution (molecular weight: $~ 78,000$, 87-89\% mol hydrolyzed; Polysciences, Warrington, PA) and continuously stirred at a speed of $600 \mathrm{rpm}$ for $3.5 \mathrm{~h}$ at room temperature, in order to evaporate/extract the organic solvent and harden the microparticles.

Microparticles incorporating PDGF were produced by coencapsulating PDGF with bovine serum albumin (BSA) (fraction V; Fisher Scientific, Fairlawn, NJ). BSA is commonly used as a carrier ${ }^{2}$ for the encapsulation and protection of bioactive molecules from the harsh organic solvents that can inactivate the bioactive molecules. BSA and PDGF were mixed together at a ratio of 1:20,000 (10 $\mu \mathrm{g}$ PDGF in $200 \mathrm{mg}$ BSA) and added to the SPLA-methylene chloride solution just before dropwise addition to the PVA solution.

The resultant microparticles were sieved using appropriatesize meshes into three size ranges: $<40,40-210$, and 210 $350 \mu \mathrm{m}$. The particles were washed several times with distilled water and freeze-dried.

Particles with size 210-350 $\mu \mathrm{m}$ were chosen for this study, following studies in which the same size range was used for the culture of osteoblastic cells.33 Microparticles incorporating BSA alone were also produced, to serve as controls. Throughout this study the following controls were used: (i) SPLA microparticles (empty, designated as SPLApart) and (ii) SPLA microparticles incorporating only BSA (designated as BSA-SPLApart).

\section{Loading efficiency}

The loading efficiency of PDGF was defined as the ratio of PDGF incorporated in the SPLA microparticles to the initial amount of PDGF. To this end, $20 \mathrm{mg}$ of SPLA microparticles incorporating PDGF (designated as PDGF-SPLApart) was dissolved overnight in $1 \mathrm{~N}$ sodium hydroxide $(\mathrm{NaOH})$, and PDGF incorporation into the microparticles (i.e., loading efficiency) was measured by enzyme-linked immunosorbent assay (ELISA) (as described in the section "Release kinetics and quantification"). BSA loading efficiency in BSASPLApart was determined by the Bradford method for protein quantification (Bio-Rad, Hercules, CA), by measuring the 
absorbance at $284 \mathrm{~nm}$ on a spectrophotometer against known BSA concentrations.

\section{Morphological characterization}

Scanning electron microscopy (Jeol 6300F; JEOL USA, Peabody, MA) was performed to examine the surface morphology of the microparticles. The lyophilized samples were carbon coated, imaged at $8 \mathrm{kV}$, and viewed at magnifications of $100 \times$ and $300 \times$.

\section{Release kinetics and quantification}

Release kinetics studies were conducted to determine the temporal release of PDGF from PDGF-SPLApart. Two hundred $\mathrm{mg}$ of PDGF-SPLApart was placed in $15-\mathrm{mL}$ conical tubes in the presence of $5 \mathrm{~mL}$ of phosphate-buffered solution containing $1 \%$ of a solution of antibiotics penicillinstreptomycin (designated PBS-AB). All samples were placed in an orbital shaker and agitated at $120 \mathrm{rpm}$ at $37^{\circ} \mathrm{C}$.

At predetermined time points, $2.5 \mathrm{~mL}$ of the release supernatant (PBS-AB) was withdrawn and replaced with the same volume of fresh PBS-AB. The supernatant was stored at $-80^{\circ} \mathrm{C}$ until analysis. The released PDGF was quantified using an ELISA kit specific for human PDGF-BB (R\&D Systems), by comparison to a standard PDGF-BB curve, according to the manufacturer's instructions. All experiments were performed at least two times.

\section{Determination of the optimal concentration of PDGF that has a mitogenic effect over MC3T3-E1 cells}

Before analyzing the biological activity of the PDGF released from SPLA microparticles, it was necessary to determine the optimal concentration of PDGF that produced a clear mitogenic effect over MC3T3-E1 cells.

Several concentrations of PDGF, ranging from 0 to $50 \mathrm{ng} /$ $\mathrm{mL}$, were tested beforehand on an MC3T3-E1 cell culture system. Cells were seeded in 12-well tissue culture plates (Corning, Lowell, MA) at a density of $12,600 \mathrm{cells} / \mathrm{cm}^{2}$. Twenty-four hours after cell seeding, the culture medium was removed and replaced by fresh DMEM supplemented with the following concentrations of PDGF: 0, 2, 4, 10, 20, and $50 \mathrm{ng} / \mathrm{mL}$. After $72 \mathrm{~h}$, DNA levels were measured by the PicoGreen double-stranded DNA (dsDNA) quantification kit (Molecular Probes, Carlsbad, CA). This is an ultrasensitive fluorescent nucleic acid stain for quantitating dsDNA in solution that allows to measure cell proliferation.

At the end of the experiment, the culture medium was removed and the monolayer was washed with $10 \times$ TrisEDTA (TE) buffer. Four hundred $\mu \mathrm{L}$ of $0.1 \mathrm{~N} \mathrm{NaOH}$ was added to the wells to cause the cells to release DNA into solution. An aliquot of the DNA suspension was removed and added to $10 \times \mathrm{TE}$ buffer, to which was then added the
PicoGreen reagent (previously prepared in $10 \times \mathrm{TE}$ ) at a 1:1 (v/v) ratio, and fluorescence was measured in a microplate reader at 485 and $535 \mathrm{~nm}$ excitation and emission wavelengths, respectively. Lambda ( $\lambda$ ) DNA was used as a standard. The results were obtained from three experiments.

\section{Evaluation of the maintenance of the biological activity of released PDGF}

When a molecule is incorporated inside a release system, it is vital that its biological activity is maintained throughout loading, incorporation, and release. Thus, it was necessary to determine if PDGF incorporated into the matrix of SPLA microparticles was still active after incorporation and release. To this end it was used as a culture of MC3T3-E1 cells.

After determining the minimal concentration of PDGF necessary to produce a mitogenic effect on MC3T3-E1 cells, the same experimental setting was used to test the samples and controls.

Briefly, cells were seeded in 12-well tissue culture plates at a density of 12,600 cells $/ \mathrm{cm}^{2}$. Twenty-four hours after cell seeding, the culture medium was removed and replaced by DMEM supplemented as described in Table 1.

After 72 and $148 \mathrm{~h}$, DNA levels were measured by the PicoGreen dsDNA quantification kit (Molecular Probes), as described above. The results were obtained from three experiments.

\section{Statistics}

Results are expressed as mean \pm standard deviation. Differences between experimental results were analyzed

Table 1. Content of Culture Medium Supplemented to a Monolayer of MC3T3-E1 Cells for the Evaluation of the Biological Activity of Released PDGF

\begin{tabular}{ll}
\hline Content of culture medium & Designation \\
\hline DMEM & Ctrl \\
$\begin{array}{l}\text { DMEM supplemented with release } \\
\text { medium PBS-AB }\end{array}$ & PBS \\
DMEM supplemented with release & Rel BSA \\
medium from BSA-SPLA microparticles & \\
DMEM supplemented with BSA & Exog BSA \\
DMEM containing $1 \mu \mathrm{L}$ of BSA-SPLA & SPLA-BSA \\
microparticles & \\
DMEM containing $1 \mu \mathrm{L}$ of empty & SPLApart \\
SPLA microparticles & \\
DMEM supplemented with 4 ng/mL & Exog PDGF \\
$\quad$ of PDGF & \\
DMEM supplemented with release & Rel PDGF \\
medium from PDGF-SPLA microparticles & \\
DMEM containing $1 \mu \mathrm{L}$ of PDGF-SPLA & PDGF-SPLApart \\
microparticles & \\
\hline
\end{tabular}


according to a Student's $t$-test, with the threshold for statistical significance set at $p<0.01$.

\section{RESULTS}

\section{Loading efficiency}

The loading efficiency was determined by subtracting the amount of the incorporated molecule (either BSA or PDGF) from the initial amount available for incorporation. Table 2 presents the values of the loading efficiencies for both BSA and PDGF.

As observed from the table, BSA incorporation is well correlated with the one for PDGF, confirming the effectiveness of BSA as a carrier/adjuvant for the incorporation of GFs, as shown elsewhere. ${ }^{2}$ The loading efficiencies were around $17 \%$ of the initial amounts of molecules, which is a low value when compared with the loading efficiencies of these same microparticles with other bioactive agents (for instance, dexamethasone). However, works in literature incorporating PDGF make use of 3-D porous scaffolds, ${ }^{35-37}$ using different materials and processing methods; therefore they are inadequate for comparison purposes.

\section{Release kinetics of PDGF-SPLA microparticles}

The cumulative release profile for PDGF is shown in Figure 1. As observed there is a burst release in the first $12 \mathrm{~h}$, which continues until $48 \mathrm{~h}$, after which a plateau is reached. This plateau is maintained until the end of the release period (8 weeks), when small amounts of PDGF are released each day from the matrix of the starch-based microparticles.

\section{Postrelease morphology}

In order to verify the integrity of the systems at the end of the release period ( 8 weeks), the morphology of the microparticles was compared with the values prior to the onset of the release study, as shown in Figures $2 \mathrm{~A}-\mathrm{C}$.

Comparing the particles before the release period (Figure 2A) and after the 8-week release period (Figure 2B), we can see considerable degradation after the 8 -week release period. Figure $2 \mathrm{~B}$ shows extensive formation of pores at the surface of the microparticles, and Figure $2 \mathrm{C}$ shows that the degradation extends to the population of particles. However, the shape of the microparticles is still maintained, with a high-porosity matrix.

Table 2. Loading Efficiencies for BSA ANd PDGF InCORPORATEd INTO THE Matrix OF SPLA Microparticles

\begin{tabular}{lc}
\hline Molecule & Loading efficiency \\
\hline BSA & $19 \pm 3 \%$ \\
PDGF & $17 \pm 1 \%$ \\
\hline
\end{tabular}

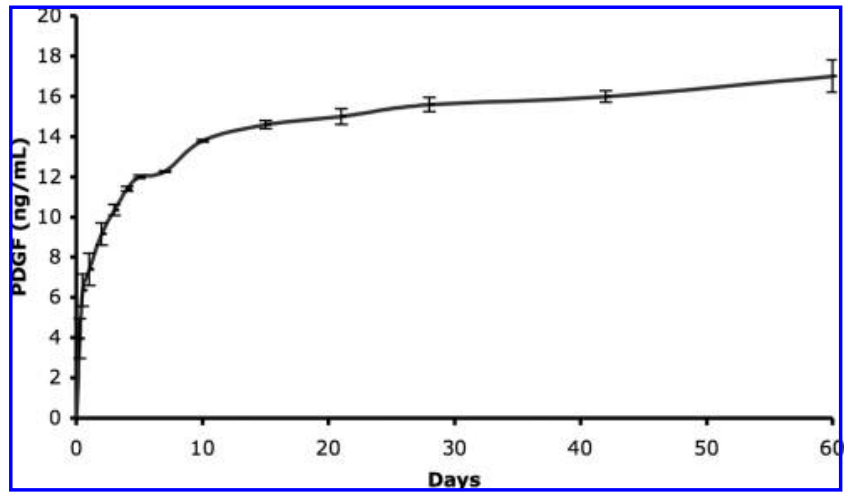

FIG. 1. Cumulative, daily release profile of PDGF up to 8 weeks from PDGF-SPLA microparticles. A burst release is observed in the initial $(12 \mathrm{~h})$ release period, after which there is a slow release until the end of the studied 8-week period.

\section{Mitogenic effect of PDGF on MC3T3-E1 cells}

The biological activity of PDGF released from the microparticles was assayed through the mitogenic effect of the bioactive agent over an osteoblastic cell line. Before evaluating the biological activity, it was necessary to determine the minimal effective concentration of PDGF that stimulates MC3T3-E1 cells to proliferate. Figure 3 reveals that almost all the concentrations tested, ranging from 2 to $50 \mathrm{ng} / \mathrm{mL}$, are capable of stimulating MC3T3-E1 proliferation, except for the $50 \mathrm{ng} / \mathrm{mL}$ concentration $(0 \mathrm{ng} / \mathrm{mL}$ vs. $50 \mathrm{ng} / \mathrm{mL}, p=0.0941)$. All other concentrations are able

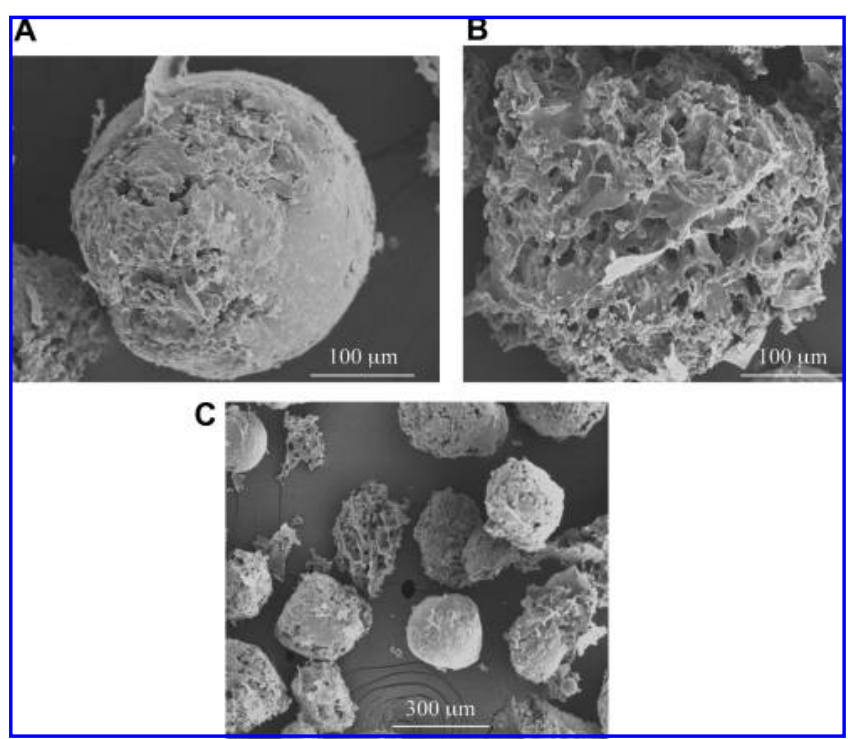

FIG. 2. Morphology of pre- and postrelease (8 weeks) PDGFSPLA microparticles. (A) Individual microparticles before the onset of the release experiment; (B) individual microparticles after the 8-week release period, evidencing massive degradation but still presenting a matrix structure; and $(\mathbf{C})$ overview of the morphology of 8-week-release microparticles, where extensive degradation is visible. 


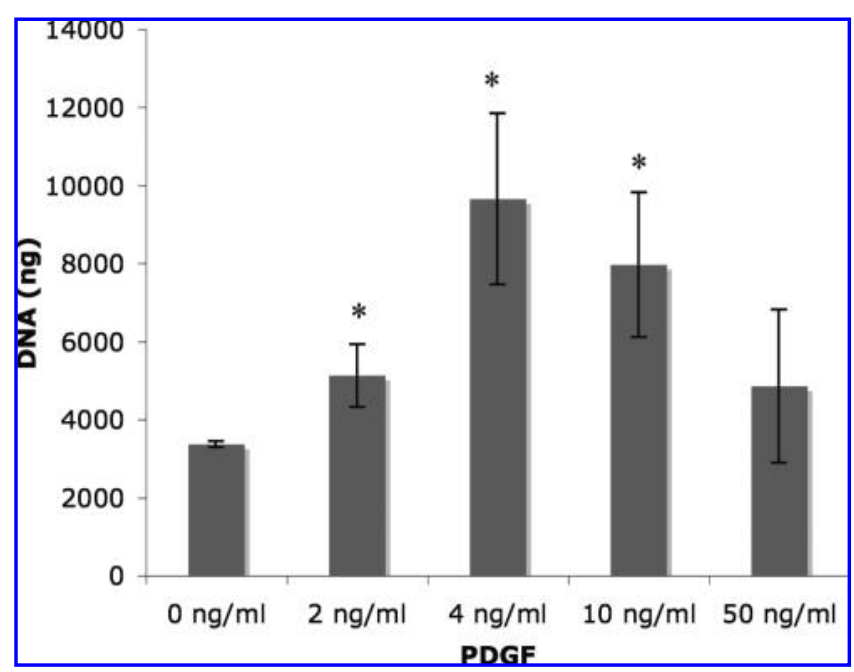

FIG. 3. Proliferative response of MC3T3-E1 cells to various concentrations of PDGF. All concentrations showed a stimulatory effect on cells, compared to control conditions. Except for $50 \mathrm{ng} / \mathrm{mL}$, all conditions were statistically different from the control conditions.

to stimulate the proliferation of cells significantly when compared to control conditions $(0 \mathrm{ng} / \mathrm{mL}$ vs. $2 \mathrm{ng} / \mathrm{mL}$, $p=0.0003 ; 0 \mathrm{ng} / \mathrm{mL}$ vs. $4 \mathrm{ng} / \mathrm{mL}, p<0.0001 ; 0 \mathrm{ng} / \mathrm{mL}$ vs. $10 \mathrm{ng} / \mathrm{mL}, p=0.0001)$. The most striking effect is observed at $4 \mathrm{ng} / \mathrm{mL}$, with a 4 -fold stimulus in proliferation compared to control.

Based on these results, $4 \mathrm{ng} / \mathrm{mL}$ was chosen as the concentration for testing the biological activity of PDGF released from starch-based microparticles.

\section{Biological activity of released PDGF}

The effect of all tested conditions over MC3T3-E1 cells was also evaluated after 3 and 6 days of culture, in order to establish the time frame and the effect of PDGF over MC3T3E1 cells. Figure 4 shows the DNA content of MC3T3-E1 cells for all tested conditions after 3 and 6 days of culture.

From the figure it is clear that the effect of PDGF over MC3T3-E1 cells is exerted in the first 3 days, after which all conditions attain a similar level of DNA content comparable to PDGF-treated cells.

Compared to cells fed with DMEM (Ctrl), both DMEM supplemented with the release supernatant of PDGF-SPLA microparticles (Rel PDGF) and DMEM supplemented with PDGF (Exog PDGF) significantly stimulate proliferation of MC3T3-E1 cells (Ctrl vs. Exog PDGF, $p=0.003$; Ctrl vs. Rel PDGF, $p<0.0001$ ) after 3 days of culture. No differences are observed in DNA content between Rel PDGF and Exog PDGF ( $p=0.8526)$, confirming that biological activity of PDGF is maintained through incorporation and release.

After 3 days of culture, all conditions containing PDGF-Exog PDGF, Rel PDGF, and DMEM containing PDGF-SPLA microparticles (PDGF-SPLApart)—are able to stimulate cell proliferation by up to 4-fold compared to control. For this time period, only the above conditions were able to significantly stimulate and increase DNA content of MC3T3-E1 cells (Table 3).

After 6 days of stimulation, all conditions, with the exception of DMEM containing empty SPLA microparticles (SPLApart) and DMEM containing PDGF-SPLA microparticles (PDGF-SPLApart), display similar DNA contents when compared with cells fed with DMEM (Ctrl).

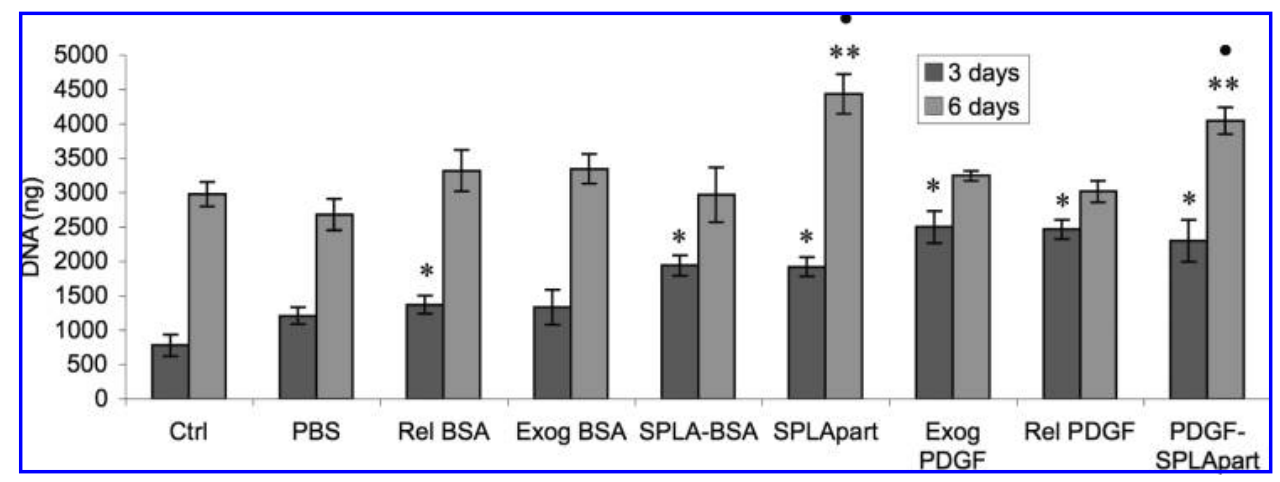

FIG. 4. DNA content at 3 and 6 days, demonstrating the effect of all conditions over MC3T3-E1 cells. At day 3 all conditions are statistically significant $(*)$ when compared to control (Ctrl), which consisted of cells fed with DMEM. At day 6 only cells fed with DMEM containing empty SPLA microparticles (SPLApart) and DMEM containing SPLA microparticles incorporating PDGF (PDGFSPLApart) had a DNA content statistically different when compared to control conditions (**), DMEM supplemented with PDGF (Exog

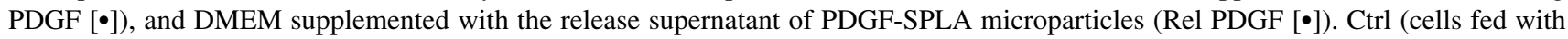
DMEM); PBS (cells fed with DMEM supplemented with PBS-AB); Rel BSA (cells fed with DMEM supplemented with release medium from BSA-SPLA microparticles); Exog BSA (cells fed with DMEM supplemented with BSA); SPLA-BSA (cells fed with DMEM containing $1 \mu \mathrm{L}$ of BSA-SPLA microparticles); SPLApart (cells fed with DMEM containing $1 \mu \mathrm{L}$ of empty SPLA microparticles); Exog PDGF (cells fed with DMEM supplemented with $4 \mathrm{ng} / \mathrm{mL}$ of PDGF); Rel PDGF (cells fed with DMEM supplemented with release medium from PDGF-SPLA microparticles at a final PDGF concentration of $4 \mathrm{ng} / \mathrm{mL}$ ); PDGF-SPLApart (cells fed with DMEM containing $1 \mu \mathrm{L}$ of PDGF-SPLA microparticles). 
Table 3. Results of the Statistical Analysis for Pairwise Comparisons at 3 days of Culture

\begin{tabular}{lcc}
\hline Pairwise comparison & $p$ values & $\begin{array}{c}\text { Statistical significance } \\
\text { (99\% confidence) }\end{array}$ \\
\hline Ctrl vs. PBS & 0.0203 & No \\
Ctrl vs. Rel BSA & 0.0049 & Yes (*) \\
Ctrl vs. Exog BSA & 0.0315 & No \\
Ctrl vs. SPLA-BSApart & 0.0007 & Yes (*) \\
Ctrl vs. SPLApart & 0.0004 & Yes (*) \\
Ctrl vs. Exog PDGF & 0.003 & Yes (*) \\
Ctrl vs. Rel PDGF & $<0.0001$ & Yes (*) \\
Ctrl vs. PDGF-SPLApart & $<0.0013$ & Yes (*) \\
\hline
\end{tabular}

These two are the only conditions that have statistically significant differences in DNA content when compared with control cells $(\mathrm{Ctrl})(* *)$ and positive controls $(\bullet)$, as shown in Table 4. This result confirms that PDGF mitogenic effect is exerted over MC3T3-E1 cells at the initial stages of the culture (3 days), after which control cells (without PDGF stimulation) reach similar DNA content.

\section{DISCUSSION}

In this study, we evaluated the incorporation of PDGF in the matrix of starch-based microparticles and posterior release. We also monitored the effect of released PDGF over cells of the osteoblastic lineage. The B isoform of PDGF was chosen because it has a greater mitogenic and chemotactic potential than PDGF-A, as well as a higher affinity to bone matrix. ${ }^{4,13}$

The loading efficiency for PDGF (Table 2), compared with those of other systems described in the literature, is rather low. ${ }^{2,38,39}$ However, in many of those systems the

Table 4. Results of Statistical Analysis for Pairwise Comparisons at 6 days of Culture

\begin{tabular}{lcc}
\hline Pairwise comparison & $p$ values & $\begin{array}{c}\text { Statistical significance } \\
(99 \% \text { confidence) }\end{array}$ \\
\hline Ctrl vs. PBS & 0.1466 & No \\
Ctrl vs. Rel BSA & 0.1688 & No \\
Ctrl vs. Exog BSA & 0.0857 & No \\
Ctrl vs. SPLA-BSApart & 0.9731 & No \\
Ctrl vs. SPLApart & 0.0017 & Yes $(* *)$ \\
Ctrl vs. Exog PDGF & 0.0746 & No \\
Ctrl vs. Rel PDGF & 0.7836 & No \\
Ctrl vs. PDGF-SPLApart & 0.0022 & Yes $(* *)$ \\
SPLApart vs. Exog PDGF & 0.0023 & Yes $(\bullet)$ \\
SPLApart vs. Rel PDGF & 0.0017 & Yes $(\bullet)$ \\
PDGF-SPLApart & 0.0027 & Yes $(\bullet)$ \\
$\quad$ vs. Exog PDGF & & \\
PDGF-SPLApart & 0.0021 & Yes $(\bullet)$ \\
$\quad$ vs. Rel PDGF & & \\
\hline
\end{tabular}

biological activity of the loaded GF is reduced during processing of the material, either by the action of organic solvents or by the inactivation of temperature. The system herein has the advantage that it is processed at room temperature and only a residual amount of organic solvent is used, therefore minimizing the risk of GF inactivation. Incorporation of PDGF into starch-based microparticles with BSA as a protecting agent ${ }^{2}$ might increase the half-life of GF (which is very short when injected free), thereby compensating the rather low loading efficiency. Although only $17 \%$ of the initial amount of the GF is loaded (which will be the subject of further optimization), the amount of GF acting on the cells can be controlled by the amount of microparticles to be incorporated into the hybrid construct. Other systems in literature present higher loading efficiencies; however, when tested for their cytotoxicity, they were found to be toxic over cells in culture, even when the cells were challenged with dilutions of leachables from the materials. ${ }^{40}$ For other systems, microparticles made of PLGA incorporating PDGF were combined with nanofibers in an attempt to control the release of the GF and to create a scaffold at the same time. ${ }^{41}$ This is a very interesting strategy, and the authors show by radioactive labeling that the biological activity of the GF is maintained. However, they do not demonstrate the same activity using a cell culture system. ${ }^{41}$

Biodegradable polymers normally display three release phases $^{42,43}$ : (i) a burst or initial period of rapid diffusion of drug located close to the surface of the polymer; (ii) a period of slow release, during which the polymer is gradually hydrolyzed in bulk; and (iii) a final release phase during which the polymer is solubilized in the aqueous environment. In our previous work, we tested the ability of starch-based microparticles to incorporate and release corticosteroids. ${ }^{34}$ We found that the release mechanisms for these systems are controlled in the initial stages by penetration of water into the structure of the microparticle, allowing the incorporated molecule to diffuse to the solution. The water uptake profile of these materials shows that the penetration of water and hence the swelling of the particles reaches $350 \%$ of the particles' weight in a few hours of immersion. ${ }^{34}$ Therefore, the release of the incorporated molecules is modulated in the initial stages by the water uptake, which causes the initial burst release observed for the first $24 \mathrm{~h}$. At later stages, the degradation of the material also plays a role in the release of the incorporated molecule. For starch-based microparticles, by 2 weeks the material had lost $20 \%$ of its weight, ${ }^{34}$ which may be accountable for the release at posterior stages. In the present work, the release profile observed for the tested time period comprises the first two of the release phases typical for biodegradable polymers, as evidenced by the (i) burst release in the first $12 \mathrm{~h}$ and (ii) a slow release, due to polymer degradation, as evidenced by the morphology at 8 weeks of release. The release profile (Figure 1) shows that the release of PDGF from starch-based microparticles is controlled by diffusion of the GF in the initial stages. While this is considered a drawback for many controlled release applica- 
tions, in this particular case, for PDGF in bone applications, it might be advantageous. Hsieh and Graves showed that pulse release of PDGF enhances the formation of mineralized matrix in vitro, while continuous application is inhibitory. ${ }^{44}$ PDGF is a potent mitogen and chemotactic agent for cells of the mesenchymal lineage, in which bone cells are included, and since proliferation and differentiation are seen as relatively uncoupled and sequential processes, it is considered to be the first-phase effector in bone. ${ }^{13}$ In this role it stimulates and recruits cells to the site in the initial stages, after which it does not seem to play a leading role in cell fate and commitment, the latter attributed to other effectors, such as bone morphogenetic proteins. In the light of these findings, the present release system can deliver PDGF in a burst to stimulate cells to migrate and expand in numbers to the defect site (in vivo) or in the hybrid construct (in vitro) and then maintain low delivery levels that will not impart the next phase of repair (maturation/differentiation). The release profile shows that after the burst release, starting at day 2 , reduced levels of PDGF are released from the microparticles. Comparing with Figure 3 , where $4 \mathrm{ng} / \mathrm{mL}$ exerts a significant effect over MC3T3-E1 cells, the fact that low amounts of GF are released up to 8 weeks will not impart cell commitment to the osteoblastic lineage.

In the present study, when determining whether PDGF incorporation in and release from starch-based microparticles would have a deleterious effect on the biological activity of the GF, it was found that the mitogenic effect of PDGF released from PDGF-SPLA microparticles was comparable to that of PDGF used to supplement DMEM culture medium (Exog PDGF). BSA has been used extensively as an adjuvant for the loading of GFs, ${ }^{2,18,45}$ to protect them from the harsh organic environment encountered during processing steps. In the present study, BSA as an adjuvant protected PDGF from methylene chloride used in the production of the microparticles. Overall, the incorporation into starch-based microparticles together with BSA would allow for the increase in the half-life of the GF, compared with the one for free GF (nonincorporated).

When comparing the effect of all conditions on the DNA content of MC3T3-E1 cells at day 3 of culture (Figure 4), the following should be highlighted:

1. The presence of PDGF significantly stimulates an increase in the DNA content when compared with the control (cells fed with DMEM culture medium [Ctrl]).

2. All other conditions seem to stimulate to some extent the DNA content of MC3T3-E1 cells. This effect, however, is not as remarkable as the one observed for PDGF-containing conditions.

3. Starch-based microparticles also seem to exert a positive effect over MC3T3-E1 cells, as evidenced by the result for empty SPLA microparticles (SPLApart).

We have shown before that $24 \mathrm{~h}$ leachables from SPLA microparticles are not toxic for MC3T3-E1 cells, as evidenced by the similar viability values as control conditions, but we do not possess enough data to support the hypothesis that degradation products from starch-based microparticles could have a stimulatory effect over the cells. At 6 days of culture, control cells reach similar DNA content compared to all other conditions, except for cells fed with DMEM culture medium containing PDGF-SPLA microparticles, which display a statistically significant increase in DNA content. MC3T3-E1 cells treated with empty SPLA microparticles (SPLApart) at day 6 of culture also present a statistically significant increase in DNA content compared to control. Since in these conditions there is an addition of microparticles to the DMEM culture medium fed to cells, we hypothesize that upon quantification, leachables from the microparticles are released into the culture medium, therefore interfering with the measurements of DNA content. However, as stated before, of primary and greater importance is the mitogenic effect of PDGF over MC3T3-E1 cells observed for 3 days of stimulation.

Cells treated with PDGF showed, besides enhanced proliferation, a fibroblast-like morphology (data not shown), in agreement to what was observed by Hsieh and Graves. ${ }^{44}$ However, the authors also report that this display of fibroblastic morphology does not impart the formation of a mineralized matrix, since cultures treated with PDGF for 3 days and then transferred to new plastic dishes exhibited a $70 \%$ increase in mineralized nodule area compared to controls. ${ }^{44}$ These results predict that multiple, brief exposures to PDGF would enhance bone formation in vivo, while prolonged exposure to PDGF, which is likely to occur in chronic inflammation, would inhibit differentiated osteoblast function and limit bone regeneration. ${ }^{44}$ This being the case, the use of this specific GF should be limited to small time periods, up to 3 days. As such, the system presented herein might be very useful in stimulating proliferation and expansion of cell number for tissue engineering applications. The present work is part of a global strategy where we aim to use this system for multiple tasks, namely to serve as substrates for the culture of cells (in dynamic conditions, such as those found in a bioreactor system) but also as carriers for biologically active agents that, upon release, can stimulate cells adhered at their surface to proliferate and/or differentiate. ${ }^{33}$ As these materials have proven to be capable of supporting cell attachment, growth, and expression of osteoblastic markers, we tested in this paper the ability of the same microparticle systems to act as carriers for PDGF. Although the incorporation efficiency is low, we believe that the biodegradable nature of starch-based materials, their biocompatibility (as shown in other works by our group) as well as the defined release profile, and the fact that the GF activity is not destroyed during the processes make this material a good candidate as a carrier for biologically active agents.

Platelets are known reservoirs of several GFs, and among them PDGF is predominant. GFs within the platelet-rich plasma are believed to mediate normal bone healing and regeneration. ${ }^{46}$ Several works have shown that platelet extracts can be applied to stimulate bone cells to proliferate. ${ }^{47-50}$ 
Bearing this in mind, rather than using a purified GF (with a high cost), an effective strategy could be to incorporate platelet extract obtained from the patients' own platelets into the above proposed carriers. This could further increase the effectiveness of the system in tissue engineering applications.

Current tissue engineering strategies involve scaffold materials and cells. We have been proposing, in a "3-in-1" strategy as described above, to use starch-based microparticles to act simultaneously as (i) biodegradable scaffold materials; ${ }^{27}$ (ii) carriers for cells; ${ }^{33}$ and, as shown in the present work, (iii) carriers for the incorporation and release of bioactive agents such as GFs.

\section{CONCLUSIONS}

In bone tissue engineering, the combination of materials possessing adequate properties (such as biocompatibility, osteoconductivity, physical and chemical properties) with site-specific cells has the potential to become a very successful means of repair. If these properties are coupled with the ability to entrap and release stimulatory molecules such as GFs with a defined temporal profile, the advantages of such a system would be several-fold.

The ability of starch-based microparticles to incorporate, release, and maintain the biological activity of PDGF was described. The release of bioactive agent occurred at greater amounts in the initial time periods (up to 3 days), when stimulation of MC3T3-E1 cell proliferation was highest. MC3T3-E1 cells were markedly stimulated to proliferate upon supplementation with PDGF, both exogenous and released from starch-based microparticles, confirming the mitogenic effect of this GF upon cells of the osteoblastic lineage and the maintenance of its biological activity after incorporation and release. After the release period extensive degradation of the microparticles was observed, but they were still able to maintain their 3-D structure.

Combined with biocompatibility, cell adhesion properties, and biological activity, the ability to release active GFs sustains the potential of starch-based microparticle systems to be used in bone tissue engineering applications.

\section{ACKNOWLEDGMENTS}

We thank George Toworfe and Jolene Bohensky for their technical help. The Portuguese Foundation for Science and Technology (FCT) is acknowledged for a Ph.D. grant to G.A. Silva (reference SFRH/BD/2001/4698). This work was partially supported by FCT through funds from the POCTI and/or FEDER programs as well as by a NIH RO1 grant, reference DE-13009. The European Union, which funded the STREP Project HIPPOCRATES (NNM-3-CT-2003505758), and the European NoE EXPERTISSUES (NMP3CT-2004-500283) are also acknowledged.

\section{REFERENCES}

1. Mitlak, B.H., Finkelman, R.D., Hill, E.L., Li, J., Martin, B., Smith, T., D'Andrea, M., Antoniades, H.N., and Lynch, S.E. The effect of systemically administered PDGF-BB on the rodent skeleton. J Bone Miner Res 11, 238, 1996.

2. Kim, H.D., and Valentini, R.F. Human osteoblast response in vitro to platelet-derived growth factor and transforming growth factor-B delivered from controlled-release polymer rods. Biomaterials 18, 1175, 1997.

3. Park, Y.J., Lee, Y.M., Lee, J.Y., Seol, Y.J., Chung, C.P., and Lee, S.J. Controlled release of platelet-derived growth factorBB from chondroitin sulfate-chitosan sponge for guided bone regeneration. J Control Release 67, 385, 2000.

4. Kozawa, O., Suzuki, A., Watanabe, Y., Shinoda, J., and Oiso, Y. Effect of platelet-derived growth factor on phosphatidylcholinehydrolyzing phopholipase D on osteoblast-like cells. Endocrinology 136, 4473, 995.

5. Hock, J.M., and Canalis, E. Platelet-derived growth factor enhances bone cell proliferation, but not differentiated function of osteoblasts. Endocrinology 134, 1423, 1994.

6. Centrella, M., McCarthy, T.L., Kusmik, W.F., and Canalis, E. Isoform-specific regulation of platelet derived growth factor activity and binding in osteoblasts-enriched culture from fetal rat bone. J Clin Invest 89, 1076, 1992.

7. Claesson-Welsh, L., and Heldin, C.H. Platelets derived growth factor. Three isoforms that bind to two distinct cell surface receptors. Acta Oncol 28, 331, 1989.

8. Fujii, H., Kitazawa, R., Maeda, S., Mizuno, K., and Kitazawa, $\mathrm{S}$. Expression of platelet derived growth factor proteins and their receptor and mRNAs during fracture healing in the normal mouse. Histochem Cell Biol 112, 131, 1999.

9. Chaudhary, L.R., and Avioli, L.V. Activation of extracellular signal-regulated kinases 1 and 2 (ERK1 and ERK2) by FGF-2 and PDGF-BB in normal human osteoblastic and bone marrow stromal cells: differences in mobility and in-gel renaturation of ERK1 in human, rat, and mouse osteoblastic cells. Biochem Biophys Res Commun 238, 134, 1997.

10. Fiedler, J., Etzel, N., and Brenner, R.E. To go or not to go: migration of human mesenchymal progenitor cells stimulated by isoforms of PDGF. J Cell Biochem 93, 990, 2004.

11. Fiedler, J., Roderer, G., Gunther, K.-P., and Brenner, R.E. BMP-2, BMP-4, and PDGF-bb stimulate chemotactic migration of primary human mesenchymal progenitor cells. $\mathrm{J}$ Cell Biochem 87, 305, 2002.

12. Mundy, G.R., Rodan, S.B., Majeska, R.J., De Martino, S., Trimmier, C., Martin, T.J., and Rodan, G.A. Unidirectional migration of osteosarcoma cells with osteoblast characteristics in response to products of bone resorption. Calcif Tissue Int 34, 542, 1982.

13. Rasubala, L., Yoshikawa, H., Nagata, K., Iijima, T., and Ohishi, M. Platelet-derived growth factor and bone morphogenetic protein in the healing of mandibular fractures in rats. Br J Oral Maxillofac Surg 41, 173, 2003.

14. Zhang, L., Leeman, E., Carnes, D.C., and Graves, D.T. Human osteoblasts synthesize and respond to platelet-derived growth factor. Am J Physiol Cell Physiol 261, 348, 1991.

15. Centrella, M., McCarthy, T.L., and Canalis, E. Plateletderived growth factor enhances deoxyribonucleic acid and collagen synthesis in osteoblast-enriched cultures from fetal rat parietal bone. Endocrinology 125, 13, 1989. 
16. Centrella, M., McCarthy, T.L., Kusmik, W.F., and Canalis, E. Relative binding and biochemical effects of heterodimeric and homodimeric isoforms of platelet-derived growth factor in osteoblast-enriched cultures from fetal rat bone. J Cell Physiol 147, 420, 1991.

17. Hock, J.M., and Canalis, E. Platelet-derived growth factor enhances bone cell replication, but not differentiated function of osteoblasts. Endocrinology 134, 1423, 1994.

18. Lee, J.-Y., Nam, S.-H., Im, S.-Y., Park, Y.-J., Lee, Y.-M., Seol, Y.-J., Chung, C.-P., and Lee, S.- J. Enhanced bone formation by controlled growth factor delivery from chitosan-based biomaterials. J Control Release 78, 187, 2002.

19. Gomes, M.E., Godinho, J.S., Tchalamov, D., Cunha, A.M., and Reis, R.L. Alternative tissue engineering scaffolds based on starch: processing methodologies, morphology, degradation and mechanical properties. Materials Science \& Engineering C-Biomimetic and Supramolecular Systems 20, 19, 2002.

20. Gomes, M.E., Ribeiro, A.S., Malafaya, P.B., Reis, R.L., and Cunha, A.M. A new approach based on injection moulding to produce biodegradable starch-based polymeric scaffolds: morphology, mechanical and degradation behaviour. Biomaterials 22, 883, 2001.

21. Gomes, M.E., Holtorf, H.L., Reis, R.L., and Mikos, A.G. Influence of the porosity of starch- based fiber mesh scaffolds on the proliferation and osteogenic differentiation of bone marrow stromal cells cultured in a flow perfusion bioreactor. Tissue Eng 12, 801, 2006.

22. Santos, M.I., Tuzlakoglu, K., Gomes, M.E., Fuchs, S., Unger, R.E., Piskin, E., Reis, R.L., and Kirkpatrick, C.J. Nano- and micro-fiber combined scaffolds: an innovative design for improving endothelial cell migration in bone tissue engineering approaches. Tissue Eng 12, 986, 2006.

23. Espigares, I., Elvira, C., Mano, J.F., Vazquez, B., San Roman, J., and Reis, R.L. New partially degradable and bioactive acrylic bone cements based on starch blends and ceramic fillers. Biomaterials 23, 1883, 2002.

24. Boesel, L.F., Mano, J.F., Elvira, C., San Román, J., and Reis, R.L. Hydrogels and hydrophilic partially degradable bone cements based on biodegradable blends incorporating starch. In Chiellini, E., and Solaro, R., eds. Biodegradable Polymers and Plastics. New York: Kluwer Academic, 2003, pp. 243-260.

25. Silva, G.A., Costa, F.J., Coutinho, O.P., Radin, S., Ducheyne, P., and Reis, R.L. Synthesis and evaluation of novel bioactive starch/bioactive glass microparticles. J Biomed Mater Res 70A, 442, 2004.

26. Silva, G.A., Costa, F.J., Pedro, A., Coutinho, O.P., and Reis, R.L. Soluble starch and composite starch-BG 45S particles: synthesis, bioactivity and interaction with rat bone marrow cells. Materials Science \& Engineering C-Biomimetic and Supramolecular Systems 25, 237, 2005.

27. Silva, G.A., Costa, F.J., and Reis, R.L. Microparticulate systems from natural origin materials: applications in tissue engineering. In: Hasirci, V., and Hasirci, N., eds. Biomaterials: From Molecules to Engineered Tissues. New York: Kluwer Academic Press, 2004, p. 201.

28. Marques, A.P., Reis, R.L., and Hunt, J.A. The biocompatibility of novel starch-based polymers and composites: in vitro studies. Biomaterials 23, 1471, 2002.

29. Mendes, S.C., Reis, R.L., Bovell, Y.P., Cunha, A.M., van Blitterswijk, C.A., and de Bruijn, J.D. Biocompatibility testing of novel starch-based materials with potential application in orthopaedic surgery: a preliminary study. Biomaterials 22, 2057, 2001.

30. Salgado, A.J., Coutinho, O.P., and Reis, R.L. Novel starchbased scaffolds for bone tissue engineering: cytotoxicity, cell culture, and protein expression. Tissue Eng 10, 465, 2004.

31. Mendes, S.C., Bezemer, J., Claase, M.B., Grijpma, D.W., Bellia, G., Degli-Innocenti, F., Reis, R.L., De Groot, K., Van Blitterswijk, C.A., and De Bruijn, J.D. Evaluation of two biodegradable polymeric systems as substrates for bone tissue engineering. Tissue Eng 9, S91, 2003.

32. Salgado, A.J., Coutinho, O.P., Reis, R.L., and Davies, J.E. In vivo response to starch-based scaffolds designed for bone tissue engineering applications. J Biomed Mater Res 80A, 983, 2005.

33. Silva, G.A., Coutinho, O.P., Ducheyne, P., Shapiro, I.M., and Reis, R.L. The effect of starch and starch-bioactive glass composite microparticles on the adhesion and expression of the osteoblastic phenotype of a bone cell line. Biomaterials 28, 326, 2007.

34. Silva, G.A., Costa, F.J., Neves, N.M., Coutinho, O.P., Dias, A.C.P., and Reis, R.L. Entrapment ability and release profile of corticosteroids from starch-based particles. J Biomed Mater Res 73A, 234, 2005.

35. Richardson, T.P., Peters, M.C., Ennett, A.B., and Mooney, D.J. Polymeric system for dual growth factor delivery. Nat Biotechnol 19, 1029, 2001.

36. Park, Y.J., Lee, Y.M., Lee, J.Y., Seol, Y.J., Chung, C.P., and Lee, S.J. Controlled release of platelet-derived growth factorBB from chondroitin sulfate-chitosan sponge for guided bone regeneration. J Control Release 67, 385, 2000.

37. Walsh, W.R., Kim, H.D., Jong, Y.S., and Valentini, R.F. Controlled-release of platelet-derived growth-factor using ethylene-vinyl acetate copolymer (Evac) coated on stainlesssteel wires. Biomaterials 16, 1319, 1995.

38. Kim, S.E., Park, J.H., Cho, Y.W., Chung, H., Jeong, S.Y., Lee, E.B., and Kwon, I.C. Porous chitosan scaffold containing microspheres loaded with transforming growth factor-B1: implications for cartilage tissue engineering. J Control Release 91, 365, 2003.

39. Lee, J.E., Kim, K.E., Kwon, I.C., Ahn, H.J., Lee, S.-H., Cho, H., Kim, H.J., Seong, S.C., and Lee, M.C. Effects of the controlledreleased TGB-B1 from chitosan microspheres on chondrocytes cultured in a collagen/chitosan/glycosaminoglycan scaffold. Biomaterials 25, 4163, 2004.

40. Desire, L., Mysiakine, E., Bonnafous, D., Couvreur, P., Sagodira, S., Breton, P., and Fattal, E. Sustained delivery of growth factors from methylidene malonate 2.1.2-based polymers. Biomaterials 27, 2609, 2006.

41. Wei, G.B., Jin, Q.M., Giannobile, W.V., and Ma, P.X. Nanofibrous scaffold for controlled delivery of recombinant human PDGF-BB. J Control Release 112, 103, 2006.

42. Berkland, C., King, M., Cox, A., Kim, K., and Pack, D.W. Precise control of PLG microsphere size provides enhanced control of drug release rate. J Control Release 82, 137, 2002.

43. Weinhold, A.R., Besseghir, K., de Zelicourt, Y., and Gurny, R. Development and evaluation in vivo of a long-term delivery system for vapreotide, a somatostatin analogue. J Control Release 52, 205, 1998.

44. Hsieh, S.-C., and Graves, D.T. Pulse application of plateletderived growth factor enhances formation of a mineralizing 
matrix while continuous application is inhibitory. $\mathrm{J}$ Cell Biochem 69, 169, 1998.

45. $\mathrm{Xu}, \mathrm{X}$. , Yee, W.-C., Hwang, P.T.K., Yu, H., Wan, A.C.A., Gao, S., Boon, K.-L., Mao, H.-Q., Leong, K.W., and Wang, S. Peripheral nerve regeneration with sustained release of poly (phosphoester) microencapsulated nerve growth factor within nerve guide conduits. Biomaterials 24, 2405, 2003.

46. Tsay, R.C., Vo, J., Burke, A., Eisig, S.B., Lu, H.H., and Landesberg, R. Differential growth factor retention by platelet-rich plasma composites. J Oral Maxillofac Surg 63, 521, 2005.

47. Dugrillon, A., Eichler, H., Kern, S., and Kluter, H. Autologous concentrated platelet-rich plasma (cPRP) for local application in bone regeneration. Int J Oral Maxillofac Surg 31, 615, 2002.

48. Gruber, R., Varga, F., Fischer, M.B., and Watzek, G. Platelets stimulate proliferation of bone cells: involvement of plateletderived growth factor, microparticles and membranes. $\underline{\text { Clin }}$ Oral Implants Res 13, 529, 2002.
49. Whitman, D.H., Berry, R.L., and Green, D.M. Platelet gel: an autologous alternative to fibrin glue with applications in oral and maxillofacial surgery. J Maxillofac Surg 55, 1294, 1997.

50. Marx, R.E., Carlson, E.R., and Eichstaedt, R.M. Platelet-rich plasma: growth factor enhancement for bone grafts. Oral Surg 85, 638, 1998

Address reprint requests to: Gabriela A. Silva, Ph.D. 3B's Research Group-Biomaterials, Biodegradables and Biomimetics Department of Polymer Engineering

University of Minho

Campus de Gualtar 4710-057 Braga Portugal

E-mail: gsilva@dep.uminho.pt 


\section{This article has been cited by:}

1. Simone S. Silva, João F. Mano, Rui L. Reis. 2010. Potential applications of natural origin polymer-based systems in soft tissue regeneration. Critical Reviews in Biotechnology 30:3, 200-221. [CrossRef]

2. Marta Alves da Silva, Albino Martins, Ana A. Teixeira, Rui L. Reis, Nuno M. Neves . 2010. Impact of Biological Agents and Tissue Engineering Approaches on the Treatment of Rheumatic DiseasesImpact of Biological Agents and Tissue Engineering Approaches on the Treatment of Rheumatic Diseases. Tissue Engineering Part B: Reviews 16:3, 331-339. [Abstract] [Full Text] [PDF] [PDF Plus]

3. Marina I. Santos, Rui L. Reis. 2010. Vascularization in Bone Tissue Engineering: Physiology, Current Strategies, Major Hurdles and Future Challenges. Macromolecular Bioscience 10:1, 12-27. [CrossRef]

4. Iva Pashkuleva, Alexandra P. Marques, Filipe Vaz, Rui L. Reis. 2010. Surface modification of starch based biomaterials by oxygen plasma or UV-irradiation. Journal of Materials Science: Materials in Medicine 21:1, 21-32. [CrossRef]

5. E. R. Balmayor, G. A. Feichtinger, H. S. Azevedo, M. Griensven, R. L. Reis. 2009. Starch-poly- $\square$-caprolactone Microparticles Reduce the Needed Amount of BMP-2. Clinical Orthopaedics and Related Research ${ }^{\circledR}$ 467:12, 3138-3148. [CrossRef]

6. A.L. Oliveira, S.A. Costa, R.A. Sousa, R.L. Reis. 2009. Nucleation and growth of biomimetic apatite layers on 3D plotted biodegradable polymeric scaffolds: Effect of static and dynamic coating conditions. Acta Biomaterialia 5:5, 1626-1638. [CrossRef]

7. E.R. Balmayor, K. Tuzlakoglu, H.S. Azevedo, R.L. Reis. 2009. Preparation and characterization of starch-poly- $\varepsilon-c a p r o l a c t o n e$ microparticles incorporating bioactive agents for drug delivery and tissue engineering applications. Acta Biomaterialia 5:4, 1035-1045. [CrossRef]

8. Biancamaria Baroli. 2009. From natural bone grafts to tissue engineering therapeutics: Brainstorming on pharmaceutical formulative requirements and challenges. Journal of Pharmaceutical Sciences 98:4, 1317-1375. [CrossRef]

9. S BAE, J SON, K PARK, D HAN. 2009. Fabrication of covered porous PLGA microspheres using hydrogen peroxide for controlled drug delivery and regenerative medicine. Journal of Controlled Release 133:1, 37-43. [CrossRef]

10. A. P. Marques, R. P. Pirraco, R. L. ReisBiocompatibility of starch-based polymers 738-760. [CrossRef] 